\title{
PHOTOGRAMMETRIC PROCESSING OF APOLLO 15 METRIC CAMERA OBLIQUE IMAGES
}

\author{
K. L. Edmundson ${ }^{\mathrm{a}, *}$, O. Alexandrov ${ }^{\mathrm{b}}$, B. A. Archinal ${ }^{\mathrm{a}}$, K. J. Becker ${ }^{\mathrm{a}}$, T. L. Becker ${ }^{\mathrm{a}}$, R. L. Kirk ${ }^{\mathrm{a}}$, Z. M. Moratto ${ }^{\mathrm{c}}$, A. V. Nefian ${ }^{\mathrm{b}}$, J. \\ O. Richie ${ }^{\text {a }}$ M. S.Robinson ${ }^{\mathrm{d}}$ \\ aAstrogeology Science Center, U.S. Geological Survey, Flagstaff, AZ, USA, 86001 - kedmundson@usgs.gov \\ bNASA Ames Research Center, Moffett Field, CA, USA, 94035 - oleg.alexandrov@nasa.gov \\ 'Google Inc., Mountain View, California, USA, 94043 - zmoratto@gmail.com \\ ${ }^{\mathrm{d} S}$ School of Earth and Space Exploration, Arizona State University, Tempe, Arizona, USA, 85287 - robinson@ser.asu.edu
}

Commission IV, WG IV/8

KEY WORDS: Apollo 15, Extra-terrestrial, Mapping, Metric Camera, Oblique, Photogrammetry

\begin{abstract}
:
The integrated photogrammetric mapping system flown on the last three Apollo lunar missions $(15,16$, and 17) in the early 1970 s incorporated a Metric (mapping) Camera, a high-resolution Panoramic Camera, and a star camera and laser altimeter to provide support data. In an ongoing collaboration, the U.S. Geological Survey's Astrogeology Science Center, the Intelligent Robotics Group of the NASA Ames Research Center, and Arizona State University are working to achieve the most complete cartographic development of Apollo mapping system data into versatile digital map products. These will enable a variety of scientific/engineering uses of the data including mission planning, geologic mapping, geophysical process modelling, slope dependent correction of spectral data, and change detection. Here we describe efforts to control the oblique images acquired from the Apollo 15 Metric Camera.
\end{abstract}

\section{INTRODUCTION}

In the early 1970 s, an integrated photogrammetric mapping system flew on the last three Apollo lunar missions AS15, AS16, and AS17 (AS refers to Apollo-Saturn, the Kennedy Space Center designation for manned Apollo flights). It included a Metric (mapping) Camera (MC), a high-resolution Panoramic Camera (PC), and a star camera and laser altimeter to provide support data (Figure 1, Figure 2; Livingston, et al., 1980). In the years following these missions, several U.S. government agencies (e.g. Defense Mapping Agency, National Oceanic and Atmospheric Administration, U.S. Geological Survey [USGS], and NASA) made significant efforts to geodetically control primarily the nadir MC photographs, producing hardcopy image mosaics and topographic contour maps (Doyle, et al., 1976; Light, et al., 1980).

Clearly, it is not possible to readily update hardcopy products (or scanned images of them) making them consistent with our rapidly improving knowledge of lunar coordinates. Further, they do not support the quantitative and detailed surface characterization needed for future landed missions. Consequently, in an ongoing collaboration, the USGS Astrogeology Science Center (ASC), the Intelligent Robotics Group of the NASA Ames Research Center (ARC), and Arizona State University (ASU), are working to achieve the most complete cartographic development of Apollo mapping system data into versatile digital map products. These have a variety of possible scientific/engineering uses including mission planning, geologic mapping, geophysical process modelling, slope dependent correction of spectral data, and change detection.

The NASA Johnson Space Center (JSC) and ASU digitized the original MC and PC film images, held in cold storage at JSC (Robinson, et al., 2008; Paris, et al., 2012a). ASU also created a

\footnotetext{
* Corresponding author
}

digital record of image support data (Paris, et al., 2012b). The ARC completed our joint project to process the nadir images from AS15-17, producing a photogrammetrically and geodetically controlled, orthorectified digital image mosaic (DIM) and digital terrain model (DTM) sampled at

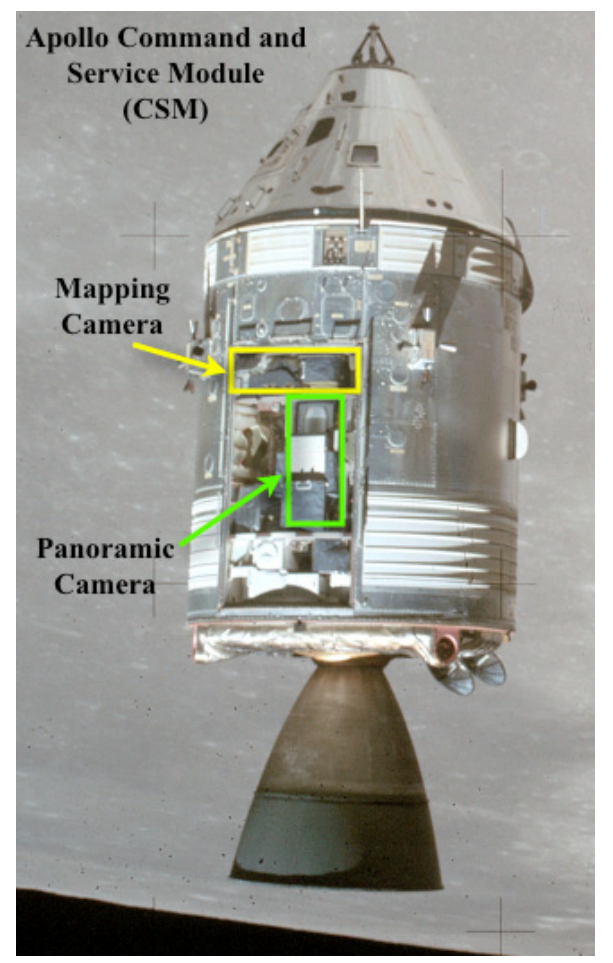

Figure 1: Apollo 15 Command and Service Module with Lunar Mapping Camera System and Panoramic Camera in the Scientific Instrument Module (from NASA image AS15-88-1197). 


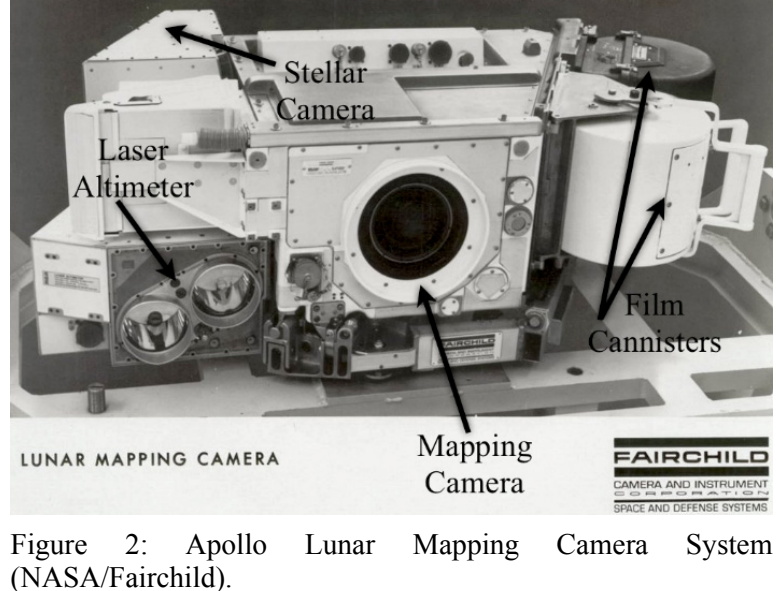

approximately $30 \mathrm{~m} /$ pixel (Nefian, et al., 2012, 2013) and tied to a reference frame based on Lunar Orbiter Laser Altimeter data (LOLA; Mazarico, et al., 2010). They accomplished this using the Ames Stereo Pipeline (ASP) software developed by the ARC (Moratto, et al., 2010) and the Integrated Software for Imagers and Spectrometers (ISIS) planetary cartography package developed by the ASC (Keszthelyi, et al., 2014).

In our initial work with digital Apollo data, we avoided processing oblique and particularly high-oblique MC images as their geometry poses additional challenges for recognizing control point features and orthorectification. However, in 1972, even before support data were available for AS16 photographs, and again in 2005, the USGS successfully demonstrated that these images could provide valuable topographic information and further, that high-oblique images can be rectified to obtain planimetric data (Wu, et al., 1972; Gaddis, et al., 2005).

In the following we outline our efforts to control the oblique AS15 MC images to one another, to the nadir AS15 MC images, and to the LOLA reference frame. We describe the lunar missions and the MC, preparation of image and support data, the photogrammetric control process itself, resulting products, and lastly, ongoing and future work.

\section{THE MISSIONS AND THE METRIC CAMERA}

Coverage from the AS15-17 cameras was limited to the illuminated portion of the near-equatorial zone spanning the ground tracks of the three missions. Figure 3 shows AS15 orbit ground tracks and $\mathrm{MC}$ photo locations. As a result of pre-flight analyses and in situ observations and measurements obtained by the landed Apollo missions (e.g., Masursky et al., 1978), this equatorial zone encompasses perhaps the most studied portion of the Moon, and these analyses have established a fundamental baseline for lunar surface characterization that is unmatched in other regions.

The MC, manufactured by the Space and Defense Systems branch of the Fairchild Camera and Instrument Corporation, was a frame camera similar to those used in terrestrial aerial photogrammetry (Doyle, 1970). Accurately calibrated prior to flight, it had a focal length of $76 \mathrm{~mm}$ and an image format of 114 square $\mathrm{mm}$ (Table 1).

At the nominal altitude of $\sim 110 \mathrm{~km}$ a nadir image covers a region of $\sim 160$ square $\mathrm{km}$. Along-track image overlap of $78 \%$ ensured sufficient stereo convergence and geometric strength for triangulation. AS15-17 acquired approximately 6,000 MC

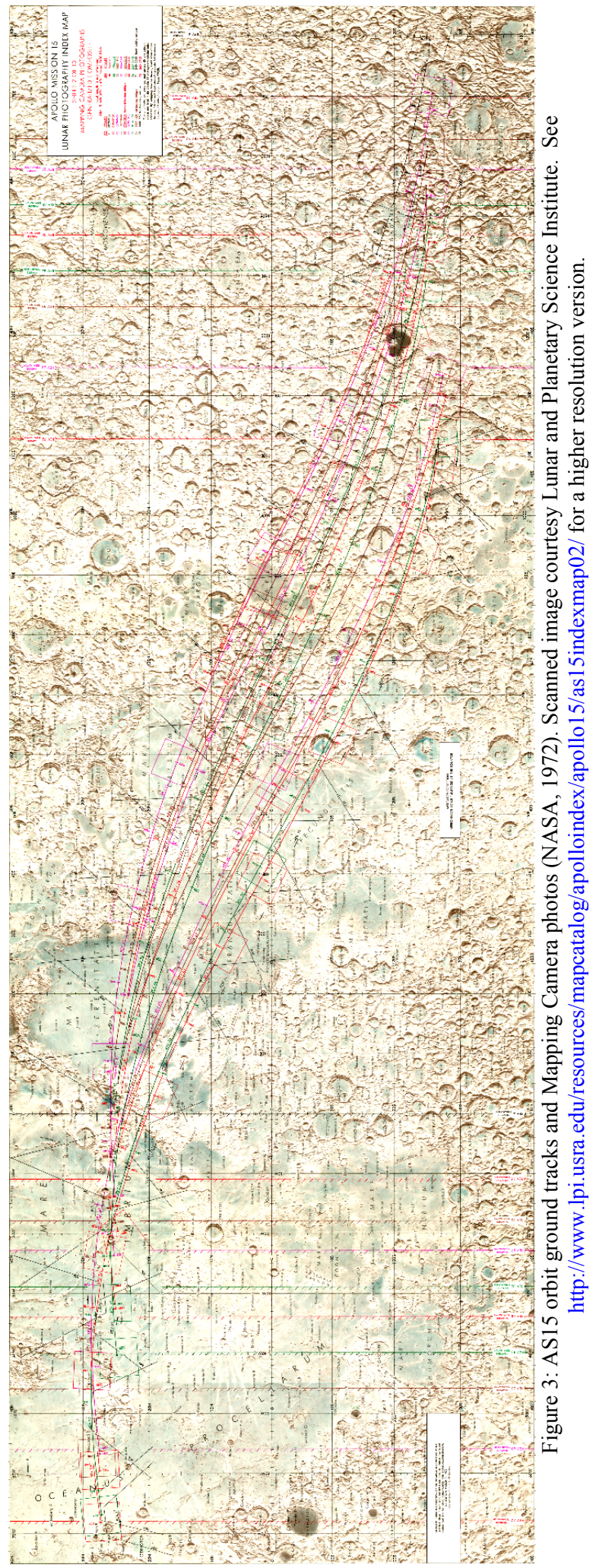


Table 1: Apollo Metric Camera characteristics (from Light, 1972).

\begin{tabular}{|c|c|}
\hline Characteristics & $\begin{array}{c}\text { Mapping Camera System } \\
\text { Terrain }\end{array}$ \\
\hline Manufacturer & $\begin{array}{l}\text { Fairchild camera \& } \\
\text { Instrument Corp. }\end{array}$ \\
\hline Basic design & Frame \\
\hline Focal length & 3 inches $(76.6 \mathrm{~mm})$ \\
\hline Lens angular coverage & $74^{\circ} \times 74^{\circ}$ \\
\hline Lens aperture & $\mathrm{f} / 4.5$ \\
\hline Lens distortion & $<50_{\mu \mathrm{m}}$ \\
\hline Filter & None \\
\hline Resolution $1 \mathrm{p} / \mathrm{mm}$ & @ $1.7: 1,58-70$ \\
\hline Reseau-interval & $10 \mathrm{~mm}$ crosses (121) \\
\hline Illumination & Natural \\
\hline Fiducials-Artificial & 2 sets of 4 \\
\hline Natural & 4 \\
\hline Shutter Type & Between Lens \\
\hline Shutter speeds & $1 / 15$ to $1 / 240 \mathrm{sec}$. \\
\hline Format & $4.5 \times 4.5$ in. \\
\hline Transmission & $44.3 \%$ \\
\hline $\begin{array}{l}\text { Film size and typical } \\
\text { type }\end{array}$ & $\begin{array}{l}5 \text { inches }(127 \mathrm{~mm}) \\
\text { Type EK } 3400 \text { or } \\
\text { EK } 3414\end{array}$ \\
\hline Magazine & 1500 feet \\
\hline Capacity & (3600 frames) \\
\hline Cycling rate & 8.5 to 34 sec. \\
\hline Motion compensation & 10 to 40 M Radians/sec. \\
\hline Exposure control & $16: 1$ Automatic \\
\hline Weight & $131 \mathrm{Lbs}$ W/Film \\
\hline Data Recording & Data Block \\
\hline Film Flattening & $\begin{array}{l}\text { Platen with moveable } \\
\text { pressure plate }\end{array}$ \\
\hline
\end{tabular}

images suitable for mapping. Of these, $3 / 4$ are nadir-looking covering $\sim 16 \%$ of the lunar surface. The remainder are oblique and increase useful coverage to $\sim 25 \%$ (Figure 4 ).

There are 2350 useful MC images from AS15 alone, 475 of which are oblique. These were acquired in four orbits with the spacecraft oriented such that the camera was tilted either $25^{\circ}$ forward or aft; or $40^{\circ}$ north or south (orbits $23,34,35$, and 71 respectively; Figure 5).
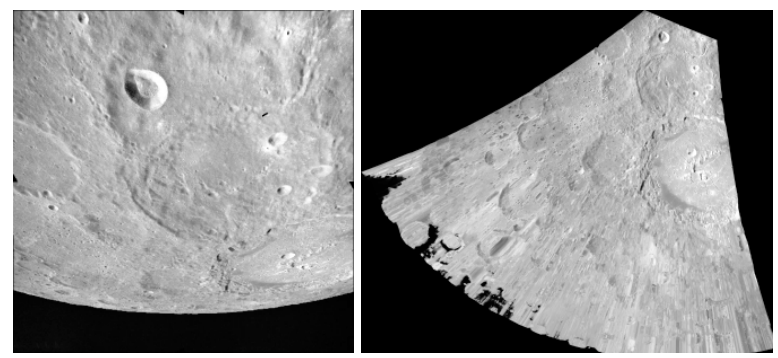

Figure 4: AS15-M-2515 (NASA/JSC/ASU) from $40^{\circ} \mathrm{S}$ oblique orbit 71. Left: raw image with limb. Right: projected image shows artifacts that may occur when projecting highly oblique data toward the limb.

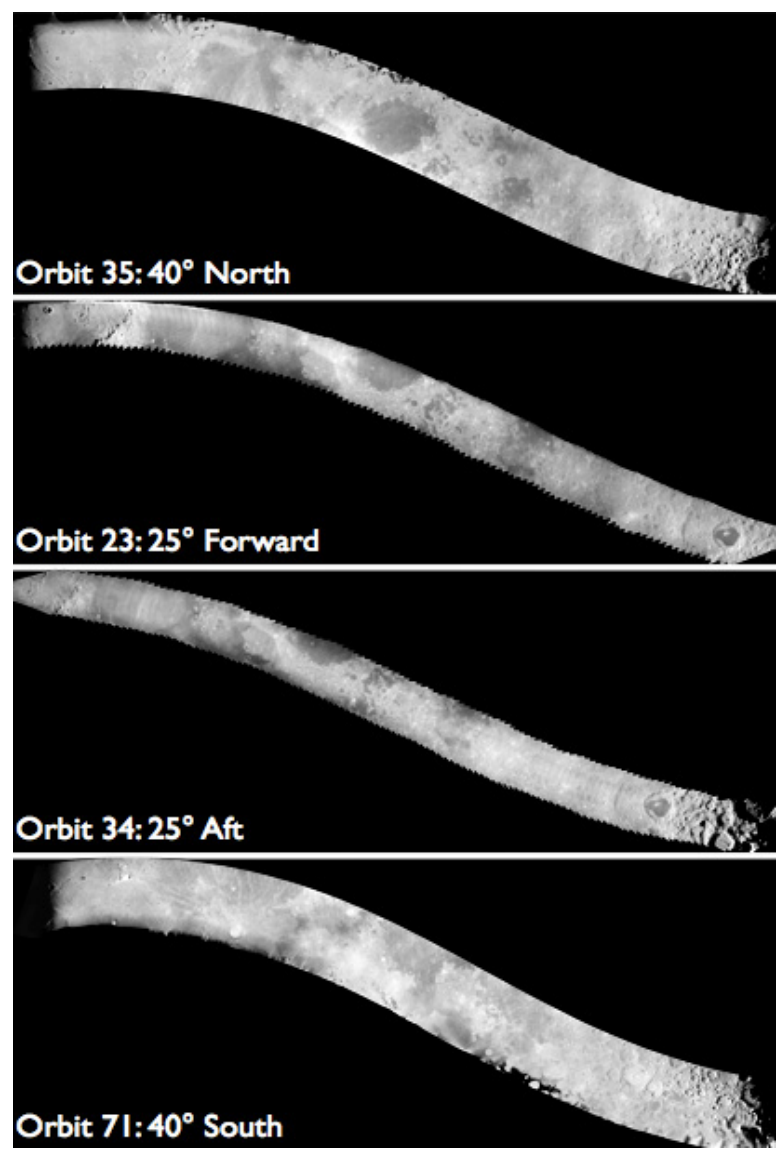

Figure 5: Preliminary controlled DIMs of AS15 oblique orbits. Images are averaged. Projection is simple cylindrical. Original resolution is $500 \mathrm{~m} / \mathrm{pixel}$.

\section{DATA PREPARATION}

\subsection{Film Scanning and Digital Image Processing}

This summary follows closely that on the ASU Apollo Image Archive (apollo.sese.asu.edu/ABOUT_SCANS/index.html; accessed 14 April 2016). The film images were removed from cold storage, acclimated to room temperature, and hand-cleaned. Digitization was performed on a Leica DSW700 photogrammetric scanner (Calarco, Dam, and Walker, 2004) modified to record 14-bit to exploit the large dynamic range of the film. Scanned pixel size is $5 \mu \mathrm{m}$, corresponding to a ground sample distance of $\sim 8 \mathrm{~m}$ for the nadir images. Background (e.g. film base and fog) and vignetting were removed from the scans. Additional processing included measuring and recording fiducial and reseau mark positions, image resampling to remove film deformation based on the reseau marks, and cosmetic removal of the reseau marks. Exposure information encoded on each film image as a pattern of dots in the margin was decoded and recorded. The processed scans are stored as 16-bit TIFF files.

\subsection{Support Data}

ASU used optical character recognition software to convert hardcopy data from the Apollo-era reconstruction of the spacecraft position and pointing for each image (Figure 6) to digital form. ASU and the ASC worked to check these values, manually correcting detected errors. With this data ASU generated preliminary spacecraft position (sp) and image pointing (c) kernels in NAIF SPICE format (Acton, 1996). 


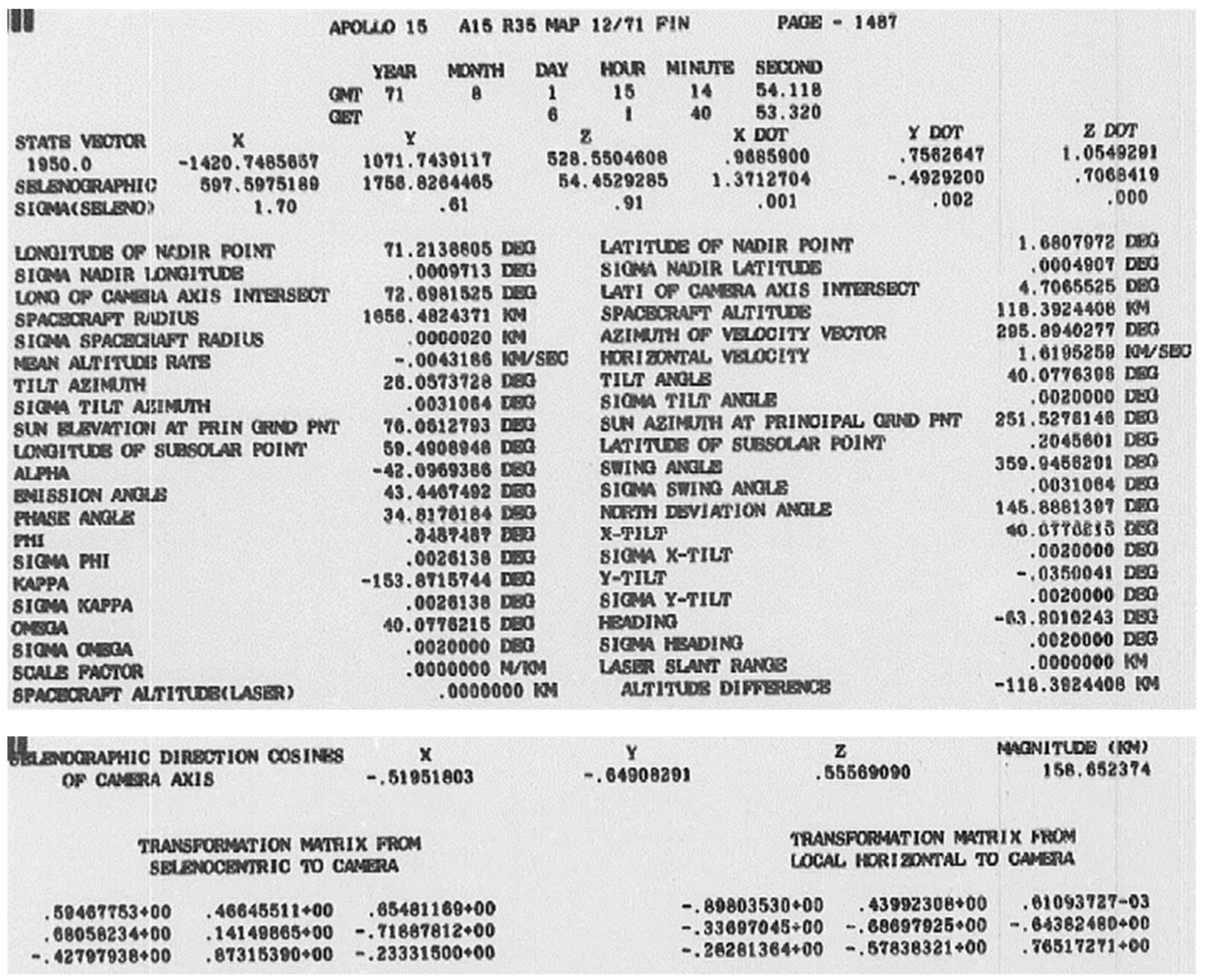

Figure 6: Support data pages for oblique image AS15-M-1487 (NASA).

\section{ISIS PROCESSING}

\subsection{ISIS Sensor Model}

ASU developed the original version of the ISIS MC sensor model. The ARC successfully utilized this model to control the AS15-17 nadir MC images. Our first attempts to control the AS15 MC oblique images exposed significant errors in the model. Correcting these necessitated recreating the preliminary $\mathrm{sp}$ and $\mathrm{c}$ kernels. For $\sim 150$ otherwise useful AS15 MC images no support data was available. For these we determined a priori spacecraft position and image pointing via interpolation or photogrammetric resection.

\subsection{ISIS Image Ingestion and Pre-Processing}

The raw TIFF MC images were converted into ISIS cube format and examined for usefulness and quality. Spacecraft hardware and blemishes in some images that could compromise feature detection and image matching were removed by masking when possible (Figure 7). The blemishes result in part from foreign debris present on the film negatives during scanning.

\subsection{Photogrammetric Control}

In ISIS, interest point detection and image matching are typically accomplished automatically with a minimal amount of operator intervention. Due to the high-oblique geometry of orbits 35 and 71 , considerable manual work was required to edit inaccurate image measurements or incorrect matches, particularly between these and the nadir orbits.

We obtained absolute horizontal control from the Lunar Reconnaissance Orbiter Wide Angle Camera (LRO WAC) mosaic (Wagner, et al., 2015) and radius values from a DTM combining data from LOLA and the SELENE (Kaguya) Terrain Camera (Barker, et al., 2015).

Bundle adjustments were performed with the ISIS program jigsaw (Edmundson, et al., 2012; Table 2). Nadir images were adjusted separately. Oblique orbits 35 and 71 were then

Table 2: Bundle adjustment statistics for AS15 MC. Results for $25^{\circ}$ oblique orbits 23 (forward) and 34 (aft) are preliminary and were previously reported in Edmundson, et al. (2014).

\begin{tabular}{r|ccccc} 
& $\begin{array}{c}\# \\
\text { images }\end{array}$ & $\begin{array}{c}\# \\
\text { tie } \\
\text { points }\end{array}$ & $\begin{array}{c}\# \\
\text { control } \\
\text { points }\end{array}$ & $\begin{array}{c}\# \\
\text { measures }\end{array}$ & $\begin{array}{c}\text { rms } \\
\text { residuals } \\
\text { (pixels) }\end{array}$ \\
\hline nadir only & 1463 & 55692 & 222 & 506439 & 1.18 \\
$23\left(25^{\circ}\right.$ fwd $)$ & 115 & 907 & 12 & 3902 & 1.54 \\
$34\left(25^{\circ}\right.$ aft $)$ & 105 & 982 & 33 & 3350 & 1.51 \\
$35\left(40^{\circ} \mathrm{N}\right)$ & 128 & 551 & 4765 & 16175 & 1.75 \\
$71\left(40^{\circ} \mathrm{S}\right)$ & 127 & 1681 & 2673 & 17873 & 1.15
\end{tabular}



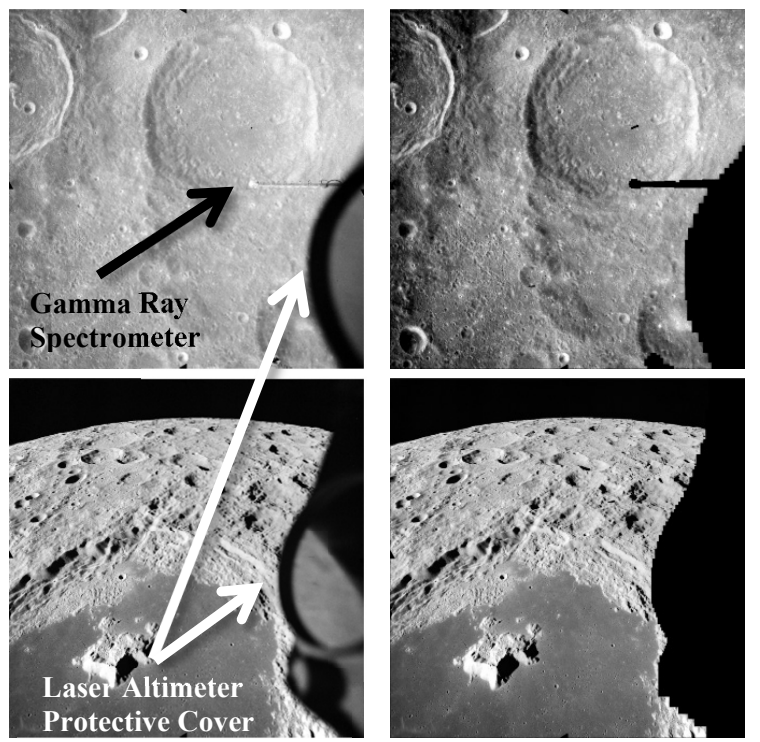

Figure 7: Hardware artifacts and blemishes before and after masking. Top: AS15-M-2095. Left - MC was not fully extended, leaving part of the Laser Altimeter protective cover in view. The Gamma Ray Spectrometer is also visible. Right - hardware is masked. Bottom: AS15-M-1442. Left - Laser Altimeter protective cover in view. Right - hardware masked. Images courtesy NASA/JSC/ASU.

individually adjusted against the updated nadir images, effectively holding the nadir fixed.

The $25^{\circ}$ oblique orbits (23 and 34) were not used in the final DIM or for DTM generation as they are redundant to the nadir image coverage. We did however control these orbits individually and to the LOLA reference frame. In the future we hope to control them to the nadir images as well.

\section{PRODUCTS}

Products resulting from this work include...

- A database of MC tie points and their adjusted 3D locations for the AS15 region consistent with the LOLA reference system.

- AS15 SPICE format spacecraft position (sp) and image pointing (c) kernels, both derived a priori from the original Apollo tracking data and as updated from the control network solutions.

- A DTM, individual orbit DIMs, and combined DIMs of the AS15 region including both nadir and oblique MC coverage.

The tie point database, DTM, and DIMs will soon be available through the USGS Astrogeology PDS Annex data portal, http://astrogeology.usgs.gov/pds/annex. Updated and a priori SPICE kernels are now available to the community via the ISIS public release. Details on DIM and DTM generation follow.

\subsection{Digital Image Mosaics}

As part of the mosaic creation process, we applied cosmetic techniques to individual images and within individual orbit mosaics to minimize variations in tone, brightness, and shadows (Figure 8). We have created controlled DIMs tied to the LOLA reference frame for 1) each individual nadir and oblique orbit; 2)
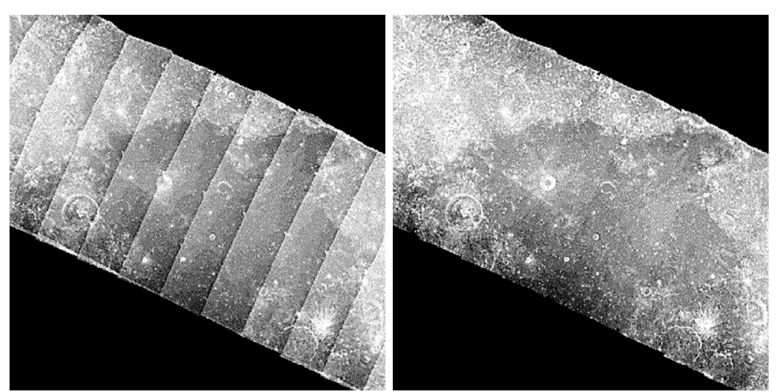

Figure 8: Cosmetic methods to minimize variation in tone, brightness, and shadows were applied within each orbit. Left: controlled raw image mosaic. Right: after adjustment, seams are notably less visible and tone more uniform. Area shown is from nadir orbit 16 centered at $2.0^{\circ} \mathrm{N}, 89.0^{\circ} \mathrm{E}$.

the nadir orbits combined; and 3 ) the nadir orbits combined with oblique orbits 35 and 71 (Figure 9, top). As the quality of the DIMs worsens with increasing obliqueness (i.e. toward the limb), the oblique orbit and combined mosaics are trimmed at an emission angle of $\sim 80^{\circ}$.

\subsection{Digital Terrain Model}

With the updated SPICE kernels from the control process, the ARC produced a DTM for the AS15 region using the ASP. Each image was coupled with its neighboring image (if available) forming a stereo pair. A DTM for each stereo pair was created. Filtering of invalid heights was performed based on triangulation error and out-of-range conditions. All stereo pair DTMs were then mosaicked together. In overlap regions, the DTMs were blended via weight functions that transition to zero towards each DTM boundary. The final product (Figure 9, bottom) was trimmed at roughly the same $80^{\circ}$ emission angle as the DIM.

\section{ONGOING AND FUTURE WORK}

We are in the process of evaluating the quality of the AS15 DTM created here. Under a separate proposal we are currently working to control the AS15 PC images. We hope to ultimately control all $\mathrm{MC}$ and PC images from AS15, AS16, and AS17.

\section{ACKNOWLEDGEMENTS}

This work has been funded by the NASA Lunar Advanced Science and Exploration Research program under contract \#NNH12AU53I. 


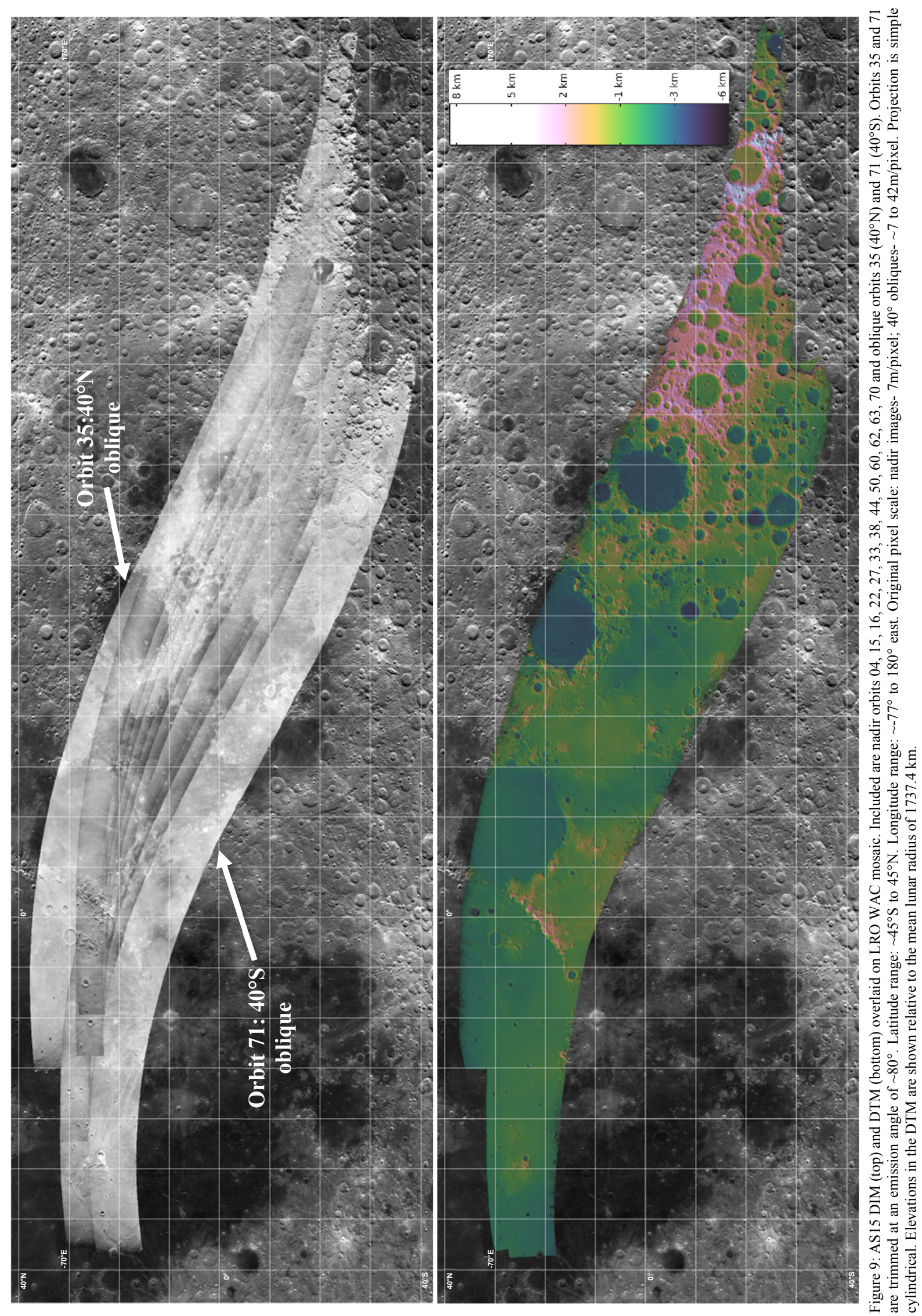




\section{REFERENCES}

Acton, C.H., 1996. Ancillary Data Services of NASA's Navigation and Ancillary Information Facility. Planetary and Space Science, 44(1), pp. 65-70.

Barker, M.K., Mazarico, E., Neumann, G.A., Zuber, M.T., Haruyama, J., and Smith, D.E., 2015. A New Lunar Digital Elevation Model from the Lunar Orbiter Laser Altimeter and SELENE Terrain Camera. Icarus, in press, doi:10.1016/j.icarus.2015.07.039.

Calarco, A., Dam, A., and Walker, S.A., 2004. Geometric Precision of Scanned Imagery for Production Photogrammetry. Int. Arch. Photogramm. Rem. Sens. Spatial Info. Sci., 34(3).

Doyle, F.J., 1970. Photographic Systems for Apollo. Photogramm. Eng., 36(10), pp. 1039-1044.

Doyle, F., Elassal, A., and Lucas, J., 1976. Experiment S-213 Selenocentric Geodetic Reference System. Geodetic Research and Development Laboratory, National Oceanic and Atmospheric Administration, Rockville, MD, and Topographic Division, U.S. Geological Survey, Reston, VA. Final Report. July.

Edmundson, K.L., Cook, D.A., Thomas, O.H., Archinal, B.A., and Kirk, R.L., 2012. Jigsaw: The ISIS3 Bundle Adjustment for Extraterrestrial Photogrammetry. ISPRS Ann. Photogramm. Remote Sens. Spatial Inf. Sci., I-4, pp. 203-208.

Edmundson, K.L, Alexandrov, O., Archinal, B.A., Becker, T.L., Moratto, Z.M., Nefian, A.V., Richie, J., and Robinson, M.R., 2014. Photogrammetric Control of Oblique Apollo 15 Metric Camera Images. Lunar and Planet Sci. XLV, Abstract 1915.

Gaddis, L.R., Skinner, J., Keszthelyi, L., Hare, T., HowingtonKraus, E., Rosiek, M., 2005. Volcanoes in Alphonsus Crater: 3D Analysis of a Future Lunar Landing Site. Space Resources Roundtable VII: LEAG Conference on Lunar Exploration, LPI 1287.

Keszthelyi, K., Becker, T., Titus, T., Sides, S., Gaddis, L., Hare, T., Kirk, R., Edmundson, K., and Anderson, J., 2014. Utilizing the Integrated Software for Imagers and Spectrometers (ISIS) to Support Future Missions. Lunar and Planet Sci. XLV, Abstract 1686.

Light, D.L., 1972. Photo Geodesy from Apollo. Photogramm. Eng., 38(6), pp. 574-587.

Light, D.L., Brown, D., Colvocoresses, A.P., Doyle, F.J., Davies, M., Ellasal, A., Junkins, J.L., Manent, J.R., McKenney, A., Undrejka, R., and Wood, G., 1980. Coordinates Derived from Apollo Metric Camera Photographs. In Manual of Photogrammetry, 4th Edition, C.C. Slama, C. Theurer, and S.W. Henriksen, Editors. American Society of Photogrammetry, Falls Church, VA, pp. 935-936.

Livingston, R.G., Berndsen, C.E., Ondrejka, R., Spriggs, R.M., Kosofsky, L.J., Van Steenburgh, D., Norton, C., Brown, D., 1980. Aerial Cameras. In Manual of Photogrammetry, $4^{\text {th }}$ Edition, C.C. Slama, C. Theurer, and S.W. Henriksen, Editors. American Society of Photogrammetry, Falls Church, VA, pp. $187-278$.

Masursky, H., Colton, G.W., and El-Baz, F., (eds.), 1978. Apollo Over the Moon - A View from Orbit, NASA, Washington, D.C., SP-362.
Mazarico, E., Neumann, G.A., Rowlands, D.D., and Smith, D.E., 2010. Geodetic constraints from multi-beam laser altimeter crossovers. Journal of Geodesy, 84(6), pp. 343-354.

Moratto, Z.M., Broxton, M.J., Beyer, R.A., Lundy, R.A., and Husmann, K., 2010. Ames Stereo Pipeline, NASA's Open Source Automated Stereogrammetry Software. Lunar and Planet Sci. XLI, Abstract 2364.

NASA, 1972. Apollo Mission 15 Lunar Photography Index Maps. Prepared under the Direction of the Department of Defense by the Aeronautical Chart and Information Center, US Air Force. Photography Index Compiled by Manned Spacecraft Center, Mapping Sciences Branch (March, 1972). [online] Available at:

$<$ www.lpi.usra.edu/resources/mapcatalog/apolloindex/apollo15/ as15indexmap02/> [Accessed 13 April 2016].

Nefian, A.V., Moratto, Z., Beyer, R., Kim, T., Broxton, M., and Fong, T., 2012. Apollo Metric Zone Terrain Reconstruction. Lunar Planet Sci., XLIII, Abstract 2184.

Nefian, A.V., Alexandrov, O., Kim, T., Moratto, Z., and Beyer, R., 2013. Albedo Reconstruction of the Apollo Metric Camera Zone. Lunar Planet Sci., XLIV, Abstract 1649.

Paris, K.N., Robinson, M.S., Lawrence, S.J., Danton, J., Bowman-Cisneros, E., Licht, A., Close, W., and Ingram, R., 2012a. The Apollo Digital Image Archive: Project Status. Lunar Planet Sci., XLIII, Abstract 2273.

Paris, K.N., Licht, A., Robinson, M.S., Bowman-Cisneros, E., and Williams, D., 2012b. Apollo Ephemeris Data. In Gaddis, L.R., Hare, T., and Beyer, R., eds. 2014. Summary of Abstracts of the Planetary Data Workshop, June 2012. U.S. Geological Survey Open-File Report 2014-1056. 199 p. [online] Available at: <http://dx.doi.org/10.3133/ofr20141056> [Accessed 15 April, 2016].

Robinson, M.S., Lawrence, S.J., Close, W., Bode, R., Grunsfeld, J.M., Ingram, R., Jefferson, L., Locke, S., Mitchell, R., Scarsella, T., White, M., Hager, M.A., Mackwell, S., Watters, T.R., Bowman-Cisneros, E., Danton, J., Speyerer, E., Dam, A., Calarco, A., and Garvin, J., 2008. The Apollo Digital Image Archive. Lunar and Planet Sci. XXXIX, Abstract 1515.

Wagner, R.V., Speyerer, E.J., Robinson, M.R., and the LROC Team, 2015. New Mosaicked Data Products from the LROC Team. Lunar and Planet Sci. XLVI, Abstract 1473.

Wu, S.S.C., Schafer, F.J., Jordan, R., and Nakata, G.M., 1972. Photogrammetry Using Apollo 16 Orbital Photography. In Apollo 16 Preliminary Science Report, NASA, Washington, D.C., SP-315, pp. $30-5$ to $30-10$. 